\title{
A lactate dehydrogenase ELISA-based assay for the in vitro determination of Plasmodium berghei sensitivity to anti-malarial drugs
}

\author{
Pamela Orjuela-Sánchez ${ }^{1 *}$, Erika Duggan ${ }^{1}$, John Nolan ${ }^{1}$, John A Frangos ${ }^{1}$ and Leonardo JM Carvalho ${ }^{1,2}$
}

\begin{abstract}
Background: Plasmodium berghei rodent malaria is a well-known model for the investigation of anti-malarial drug efficacy in vivo. However, the availability of drug in vitro assays in P. berghei is reduced when compared with the spectrum of techniques existing for Plasmodium falciparum. New alternatives to the current manual or automated methods described for $P$. berghei are attractive. The present study reports a new ELISA drug in vitro assay for $P$. berghei using two monoclonal antibodies against the parasite lactate dehydrogenase (pLDH).

Methods: This procedure includes a short-in vitro culture, the purification of schizonts and the further generation of synchronized mice infections. Early stages of the parasite are then incubated against different concentrations of anti-malarial drugs using micro-plates. The novelty of this procedure in $P$. berghei relies on the quantification of the drug activity derived from the amount of pLDH estimated by an ELISA assay using two monoclonal antibodies: 14C1 and

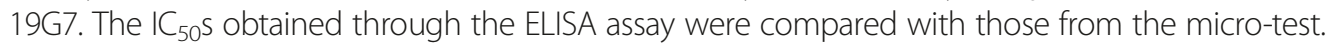

Results: The initial parameters of the synchronized samples used in the in vitro assays were a parasitaemia of $0.5 \%$ and haematocrit of $1 \%$, with an incubation period of 22 hours at $36.5^{\circ} \mathrm{C}$. pLDH detection using a $14 \mathrm{C} 1$ coating at $10 \mu \mathrm{g} / \mathrm{ml}$ and $19 \mathrm{G} 7$ at $2.5 \times 10^{-3} \mathrm{\mu g} / \mathrm{ml}$ provided good readouts of optical densities with low background in negative controls and specific detection levels for all parasite stages. $I C_{50} S$ values derived from the ELISA assay for artesunate, chloroquine, amodiaquine and quinine were: $15,7,2$, and $144 \mathrm{nM}$, respectively. When artesunate and chloroquine $\mathrm{IC}_{50} \mathrm{~S}$ were evaluated using the micro-test similar values were obtained.

Conclusion: This ELISA-based in vitro drug assay is easy to implement, fast, and avoids the use radioisotopes or expensive equipment. The utility of this simple assay for screening anti-malarial drug activity against $P$. berghei in vitro is demonstrated.

Keywords: Plasmodium berghei, In vitro culture, schizont, synchronized infection, drug in vitro assay, anti-malarials, $\mathrm{I}_{50}$ values, lactate dehydrogenase, ELISA

\section{Background}

Murine malaria models have contributed to the understanding of the biology and pathology of human malarias. Although the immune system and drug pharmacokinetics between humans and rodents may be different, the drug sensitivity profile between these Plasmodium species is mostly shared. Drug efficacy studies in small rodents have been mainly performed in vivo using

\footnotetext{
* Correspondence: posanchez@ljbi.org

'La Jolla Bioengineering Institute, 3535 General Atomics Court, Suite 210, San Diego, California (CA) 92121, USA

Full list of author information is available at the end of the article
}

different strains of Plasmodium berghei and the classical four-day suppressive test [1]. The use and development of in vitro techniques for anti-malarial drug-screening in $P$. berghei has been less prominent, especially when compared with the variety of in vitro assays described for Plasmodium falciparum. In vitro assays are complementary to in vivo tests, and in P. berghei some advantages of the in vitro assays include: i) the measurement of intrinsic anti-malarial activity, excluding confounding factors from the host such as the immune system; ii) the evaluation of larger number of compounds in one experiment with possible prediction of an in vivo

\section{Biomed Central}


outcome, and iii) the identification of discrepancies in the sensitivity profiles of $P$. berghei and P. falciparum.

Different drug in vitro assays have been adapted and developed for P. berghei. These assays include: the WHO schizont maturation test (micro-test) [2], the radioisotopic assay [3] and the measurement of parasite nucleic acids using fluorescent dyes and flow cytometry $[4,5]$. More recently, a luminescence assay using a transgenic line of $P$. berghei expressing luciferase was also developed [6]. These techniques can be limited by labour-intensive steps, disposal of radioactive waste and high costs.

Early studies of the metabolic pathways of Plasmodium led to the identification of enzymes structurally different from the host, such as lactate dehydrogenase (LDH) [7]. Plasmodium parasites require intense LDH activity to ensure the high metabolism of carbohydrates during the complex intraerythrocytic cycle [8]. These singularities pointed to parasite LDH (pLDH) detection as a good target for the development of colorimetric [9] and ELISA [10] based drug in vitro assays for P. falciparum. The aim of this study was to develop an in vitro enzyme-linked immunosorbent drug assay for P. berghei, using two monoclonal antibodies against pLDH and the semi-automated micro-dilution technique [11]. This in vitro susceptibility test starts with $P$. berghei mouse infections followed by a short in vitro culture and a synchronization procedure to generate the $P$. berghei samples to be evaluated in the drug in vitro assays. The measurement of drug activity is derived from the relative amount of $P$. berghei LDH (estimated by ELISA) as a function of the drug concentration.

\section{Methods}

Short-term parasite in vitro culture and synchronization 13-week old C57BL/6 (The Jackson Laboratory, Sacramento, CA) mice were infected intraperitoneally (IP) with $1 \times 10^{3} P$. berghei ANKA (PbA) or P. berghei ANKA expressing GFP (PbAGFP) [12] (a donation from the Malaria Research and Reference Reagent Resource Center (MR4), Manassas, VA; deposited by MF Wiser and M Hollingdale and CJ Janse and AP Waters, respectively; MR4 number: MRA-671 and MRA-865). At a parasitaemia of 2 - 3\%, mice were anesthetized (ketamine, 150 $\mathrm{mg} / \mathrm{kg}$ and xylazine, $10 \mathrm{mg} / \mathrm{kg}$ ) and $0.5 \mathrm{ml}$ of blood was collected by retro-orbital puncture, after which mice were euthanized by an IP injection of Euthasol $(100 \mathrm{mg} / \mathrm{kg})$. Animal handling and care followed the NIH Guide for Care and Use of Laboratory Animals. All protocols were approved by the La Jolla Bioengineering Institutional Animal Care and Use Committee.

Infected heparinized blood samples were washed twice in phosphate-buffered saline (PBS) solution and cultured in media RPMI 1640 (Gibco, Life Technologies) supplemented with $20 \%$ inactivated fetal bovine serum (complete RMPI) following the procedures described by Janse and Waters [13]. Cultures were flushed with a standard gas mixture of $5 \% \mathrm{O}_{2}, 5 \% \mathrm{CO}_{2}, 90 \% \mathrm{~N}_{2}$ and incubated for 22 hours at $36.5^{\circ} \mathrm{C}$. Purification of fully mature schizonts from uninfected red blood cells or younger parasites' stages was performed following the protocol described by Janse et al. [14] with some modifications. Briefly, $25 \mathrm{ml}$ of the overnight parasite culture was transferred to a $50 \mathrm{ml}$ falcon tube (Becton, Dickinson) and $8 \mathrm{ml}$ of $55 \%$ Nycodenz (v/v, PBS) was added to the bottom of the tube. Tubes were centrifuged at $450 \mathrm{~g}$ in a swing-out rotor for 30 minutes without brake. After centrifugation, the visible suspended brown ring containing mostly mature schizonts was carefully collected into another falcon tube. Schizonts were washed in complete RPMI media, resuspended in $100 \mu \mathrm{l}$ of PBS and injected intravenously (IV) into the pre-warmed tails of 13-week old C57BL/6 mice. Between 48 to 72 hours post-infection, an optimal synchronized parasitaemia of 1 to $3 \%$ was reached. Mice were anesthetized as previously described and parasite blood samples were collected. To adjust the parasitaemia and haematocrit for the in vitro assay samples, a pool of blood from uninfected mice was also gathered.

Mice parasitaemia and synchronized infections of P. berghei were analysed by flow cytometry and Hemacolor (Merck) stained thin blood smears. Tail blood samples from infected and uninfected mice were diluted 100-times in PBS, and subsequently acquired in a FACSCalibur cytometer (Becton Dickinson). Samples were excited using a $488 \mathrm{~nm}$ argon laser and GFP emission was detected with a $530 / 30 \mathrm{~nm}$ band pass filter. FCS Express (De novo Software) was used for all flow cytometry analyses by first gating for intact erythrocytes by side scatter and forward scatter parameters, and subsequently determining the proportion of GFP positive cells. The fluorescence intensity and the forward-scattered light of at least 10,000 cells per sample were measured. A negative control sample from an uninfected mouse was tested in parallel to define the threshold of positivity for the parasitaemia.

\section{Drug in vitro assays}

The anti-malarial drugs evaluated in the in vitro assays were: chloroquine diphosphate salt, amodiaquine dihydrochloride dihydrate, quinine hydrochloride dihydrate and artesunate (all from Sigma-Aldrich). The drugs were diluted in ethanol $70 \%(\mathrm{v} / \mathrm{v}$, ultrapure water) with the exception of chloroquine that was diluted in ultrapure water. The stock solutions of each drug were used to prepare two-fold dilution series in complete RPMI medium. The dilutions ranging from: 3.8-240 nM chloroquine, 1-65 nM amodiaquine, 50-3150 nM quinine-HCL and 0.6-40 nM artesunate were distributed 
(25 $\mu$ l per well) in 96-well plates (Corning, Life Science) where the drug in vitro assays were performed.

Uninfected and infected red blood cells containing primarily early trophozoites were washed twice in PBS prior to use in the in vitro assays. Infected red blood cells were diluted in complete RPMI medium to a final parasitaemia of $0.5 \%$ and $1 \%$ of haematocrit and dispensed ( $225 \mu \mathrm{l}$ per well) into the pre-dose drug plates. In each experiment, wells with uninfected and infected red blood cells without drug were included as negative and positive controls of growth, respectively. In addition, aliquots from the positive controls were frozen immediately in order to assess pLDH activity at time zero of incubation. The drug in vitro plates were incubated in gas atmosphere of $5 \% \mathrm{CO}_{2}, 5 \% \mathrm{O}_{2}$, and $90 \% \mathrm{~N}_{2}$ at $36.5^{\circ} \mathrm{C}$ for 22 to 24 hours. At the end of the incubation period, thin blood smears of positive controls were performed to confirm the presence of mature schizonts (with 8 to 16 merozoites).

The drug concentrations that inhibited $50 \%$ of parasite growth (measured by optical densities - ODs in the ELISA assays) compared to the control samples without drug $\left(\mathrm{IC}_{50} \mathrm{~s}\right)$ were calculated using HN-NonLin [15]. Drug-response curves were plotted in GraphPad Prism. Data were expressed as mean \pm standard deviation (SD), unless otherwise indicated.

\section{Enzyme-linked immunosorbent assay}

Monoclonal antibodies 14C1 (a kind donation of Dr. Michael Makler) and 19G7 (purchased from Flow Inc., Portland, OR) developed for pLDH-based malaria diagnostic tests [16] were used as capture and detection antibodies, respectively (these monoclonal antibodies are now owned by AccessBio, Somerset, NJ). Biotinylation of 19G7 $(10 \mu \mathrm{g} / \mathrm{ml})$ was carried out using the EZLink Sulfo-NHS-LC-Biotinylation Kit (Pierce Biotechnology) following the standard protocols provided by the manufacturer. The 2-(4-hydroxyazobenzene) benzoic acid (HABA) assay also included in the EZ-Link Sulfo-NHS-LC-Biotinylation Kit was used for measuring the level of biotin incorporation per immunoglobulin molecule.

The ELISA technique described above was standardized from the DELI assay developed for P. falciparum with modifications [10]. Nunc MaxiSorp flat-bottom 96 well plates (Gibco) were coated with $100 \mu \mathrm{l}$ of capture antibody $14 \mathrm{C} 1(10 \mu \mathrm{g} / \mathrm{ml})$ and incubated at $4^{\circ} \mathrm{C}$ for 24 hours. Plates were washed with phosphate-buffered saline (PBS) $0.025 \%(\mathrm{v} / \mathrm{v})$ Tween 20 (PBS/Tween) and blocked with 1\% (w/v) Bovine Serum Albumin Fraction $\mathrm{V}$ (Roche) (PBS/BSA). After 24 hours of incubation at $4^{\circ} \mathrm{C}$, the plates were washed, covered with plastic seals, refrigerated and used within a month.

Once the drug in vitro assays were performed, the plates were frozen/thawed three-times and the haemolyzed samples were homogenized. $100 \mu \mathrm{l}$ of haemolyzed samples, undiluted and diluted (1:10, 1:50 and 1:100 in PBS), was transferred into the coated ELISA plates and incubated for 1 hour at $37^{\circ} \mathrm{C}$. The plates were washed and $100 \mu \mathrm{l}$ of a 1:4,000 dilution $\left(2.5 \times 10^{-3} \mu \mathrm{g} / \mathrm{ml}\right)$ of $19 \mathrm{G} 7$ biotinylated antibody was added. After 1 hour of incubation at $37^{\circ} \mathrm{C}$, plates were washed and incubated for 30 minutes with $100 \mu \mathrm{l}$ of a 1:10,000 dilution $(0.125 \mu \mathrm{g} / \mathrm{ml})$ of peroxidaseconjugated streptavidin preparation $(1.25 \mathrm{mg} / \mathrm{ml})$ (Pierce Biotechnology). After the last wash, $100 \mu \mathrm{l}$ of TMB (3,3',5,5'-tetramentylbenzidine) (1-Step Ultra TMB-ELISA, Thermo Scientific) was added to the plate and incubated for 20 minutes at room temperature. The reaction was stopped by adding $100 \mu \mathrm{l}$ of $2 \mathrm{M} \mathrm{H}_{2} \mathrm{SO}_{4}$ solution, and read at $450 \mathrm{~nm}$ in a $\mu$ Quant micro-plate spectrophotometer (Bio-Tek Instruments).

\section{Results and discussion}

Initial ELISA assays aimed to evaluate the antibody recognition capability of PbAGFP samples and establish the optimal antibody concentrations to be used. ELISA assays were first conducted in uncultured and asynchronous parasites adjusted to $1 \%$ and $2.5 \%$ of parasitaemia and haematocrit, respectively. Initial coating plates concentrations $(10,50$ and $100 \mu \mathrm{g} / \mathrm{ml})$ of primary antibody (14C1) versus the secondary antibody (19G7) $\left(1: 1,000[0.01 \mu \mathrm{g} / \mathrm{ml}]\right.$ to $1: 64,000\left[1.56 \times 10^{-4} \mu \mathrm{g} / \mathrm{ml}\right]$ two-fold dilution) were tested. These preliminary experiments showed that independently from the coating concentration used, dilutions of the secondary antibody below 1:6,000 $\left(1.67 \times 10^{-3} \mu \mathrm{g} / \mathrm{ml}\right)$ did not significantly differ in their antigen detection capability. Using a concentration of $10 \mu \mathrm{g} / \mathrm{ml}$ of $14 \mathrm{C} 1$ and a $1: 4,000$ dilution $\left(2.5 \times 10^{-3} \mu \mathrm{g} / \mathrm{ml}\right)$ of $19 \mathrm{G} 7$, the assay generated absorbance values of $2.7( \pm 0.01)$ for infected samples and 1.2 $( \pm$ 0.01) for negative controls: uninfected blood and complete RPMI media. Based on these preliminary results, next assays attempted to reduce the high absorbance values obtained for the negative controls. Simple modifications were performed: (i) reduced the haematocrit of the samples to $1 \%$, (ii) supplemented the PBS used for washes with Tween-20 0.05\%, (iii) and performed and extra wash at all ELISA steps (four in total). These basic protocol changes significantly reduced the absorbance from the negative controls from $1.2( \pm 0.01)$ to $0.2( \pm 0.02)$ whereas the infected samples still showed good detection levels $(1.5 \pm 0.3)$.

Parasite blood samples used in these preliminary tests were uncultured and asynchronous with different stages of the parasite producing different levels of pLDH. Since the in vitro drug method proposed here is based on the schizont maturation inhibition assay [2], next experiments were directed to evaluate the ELISA standardized conditions in late stages of PbAGFP. The P. berghei life 
cycle takes approximately 24 hours and under static in vitro culture conditions the asynchronous parasites from the mice infection develop into mature schizonts that do not burst in culture. Two different parasitaemias $(0.5 \%$ and $1 \%)$ of cultured mature schizonts obtained after 22 hours of in vitro culture were evaluated in the ELISA assays. Since the absorbance expected for these stages was the highest [17], three different dilutions (1:2, 1:10 and 1:50 in PBS) of the samples were tested. The performance of the ELISAs using a $0.5 \%$ or $1 \%$ parasitaemia showed no critical differences and both worked well. At $0.5 \%$ parasitaemia, culture dilution 1:10 resulted in absorbance values in the range of 2.2 to $1.3(1: 2,000$ $\left[5.0 \times 10^{-3} \mu \mathrm{g} / \mathrm{ml}\right]$ to $1: 6,000\left[1.67 \times 10^{-3} \mu \mathrm{g} / \mathrm{ml}\right]$ secondary antibody dilution, respectively) (Figure 1 ). At $1 \%$ parasitaemia, both 1:2 and 1:10 culture dilutions resulted in high absorbance values (between 4.0 and 2.6, except at $1: 6,000$ secondary antibody dilution, absorbance $=1.8$ ). Signal-to-noise ratios at culture dilution 1:50 were not as good as dilution 1:10. It was concluded therefore that in cultures with $0.5 \%$ parasitaemia diluted $1: 10$, any of these 19G7 dilutions were appropriate. Dilution 1:4,000 $\left(2.5 \times 10^{-3} \mu \mathrm{g} / \mathrm{ml}\right)$ of $19 \mathrm{G} 7$ was selected for further use in this study as it provided a better signal-to-noise ratio than 1:6,000, and allowed using lower amount of secondary antibody than dilution 1:2,000. For cultures at $1 \%$ parasitaemia, the combination of 1:10 culture dilution with 19G7 dilution 1:6,000 would be appropriate as well. The use of different combinations does not seem to be critical for the assay, as long as the absorbance values fall within the non-saturation (non-plateau) range. As can be seen in Figure 1, the plateau is far from being reached at 1:10 dilutions (that is, 1:2 dilutions still provide absorbance values well above those observed with 1:10 dilutions).

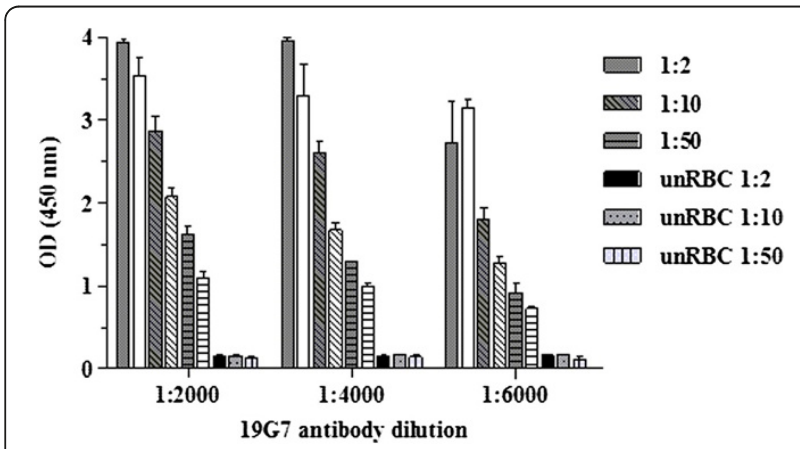

Figure 1 Effect of sample dilution in pLDH detection - ELISA standardization. Vertical bars represent mean optical density (OD) values \pm SD obtained from PbAGFP cultured schizonts at $0.5 \%$ or 1 $\%$ of parasitaemia and uninfected red blood cells (unRBC) at 1\% of haematocrit. Grey and white bars represent schizonts culture at 1\% and $0.5 \%$ of parasitaemia, respectively. Three different concentrations of 19G7 (secondary antibody) were tested (X-axis). Mean is derived from three independent assays.
The development of $P$. berghei in mice is relatively asynchronous and unsuitable for schizont inhibition assays, since most of the anti-malarial drugs are parasite stage-specific. In P. falciparum, synchronization can be easily performed by sorbitol treatment [18]. However due to alterations in the permeability of murine erythrocytes this procedure is less efficient in P. berghei [19]. A suitable alternative for $P$. berghei synchronization is the development of synchronous infections in mice. Following the procedures described by Janse and Waters [13], synchronized infections of PbA and PbAGFP were generated and followed by thin blood smears and/or flow cytometry (Figure 2). PbAGFP express GFP throughout the whole life cycle and displays different GFPfluorescence intensity during each stage [12] facilitating the analyses of mice synchronized infections by flow cytometry. As expected, asexual blood stages of PbAGFP with different parasite stages were found during the course of the infection (Figure 2, histogram B). Once the parasites were collected from the mice and cultured overnight, a highly pure and concentrated population of mature schizonts was gathered through the use of the Nycodenz gradients (Figure 2, histogram C). Collected schizonts (approximately $1 \times 10^{7}$ ) were then injected IV into mice and 30 hours post-infection a highly synchronized parasitaemia of 1-3\% was observed (Figure 2, histograms D to F). This procedure allowed the acquisition of the early stage parasite samples required for the conduction of the drug in vitro assays. This protocol was also useful for PbA (wild type, not expressing GFP) synchronization but parasite development was only followed by thin blood smears.

After having standardized the synchronized infections in mice, the next objective was to confirm the capability of the ELISA assay to detect pLDH activity throughout the different stages of the parasite life cycle in samples that were grown under the in vitro assay conditions. To do this, parasites from synchronized infections were collected in early stages of development (early trophozoites adjusted to $1 \%$ of haematocrit and $0.5 \%$ of parasitaemia) and short-cultured in 96-well plates. Incubation of plates was performed at $36.5^{\circ} \mathrm{C}$ in a desiccator plastic chamber filled with a sterile gas mixture $\left(5 \% \mathrm{CO}_{2}, 5 \% \mathrm{O}_{2}\right.$, and $\left.90 \% \mathrm{~N}_{2}\right)$. Higher incubation temperatures $\left(37^{\circ} \mathrm{C}\right.$ and $37.5^{\circ} \mathrm{C}$ ) were also tested but under these conditions parasites did not develop into mature schizonts and the presence of degenerated schizonts was common. Over the 22 hours of the incubation period parasite samples were collected at different time points in order to perform thin blood smears and the measurement of pLDH activity. In Figure 3 it can be observed how pLDH levels increased as the parasite grew during the incubation time. Ring samples at time 0 of incubation had an initial OD value of 0.25 


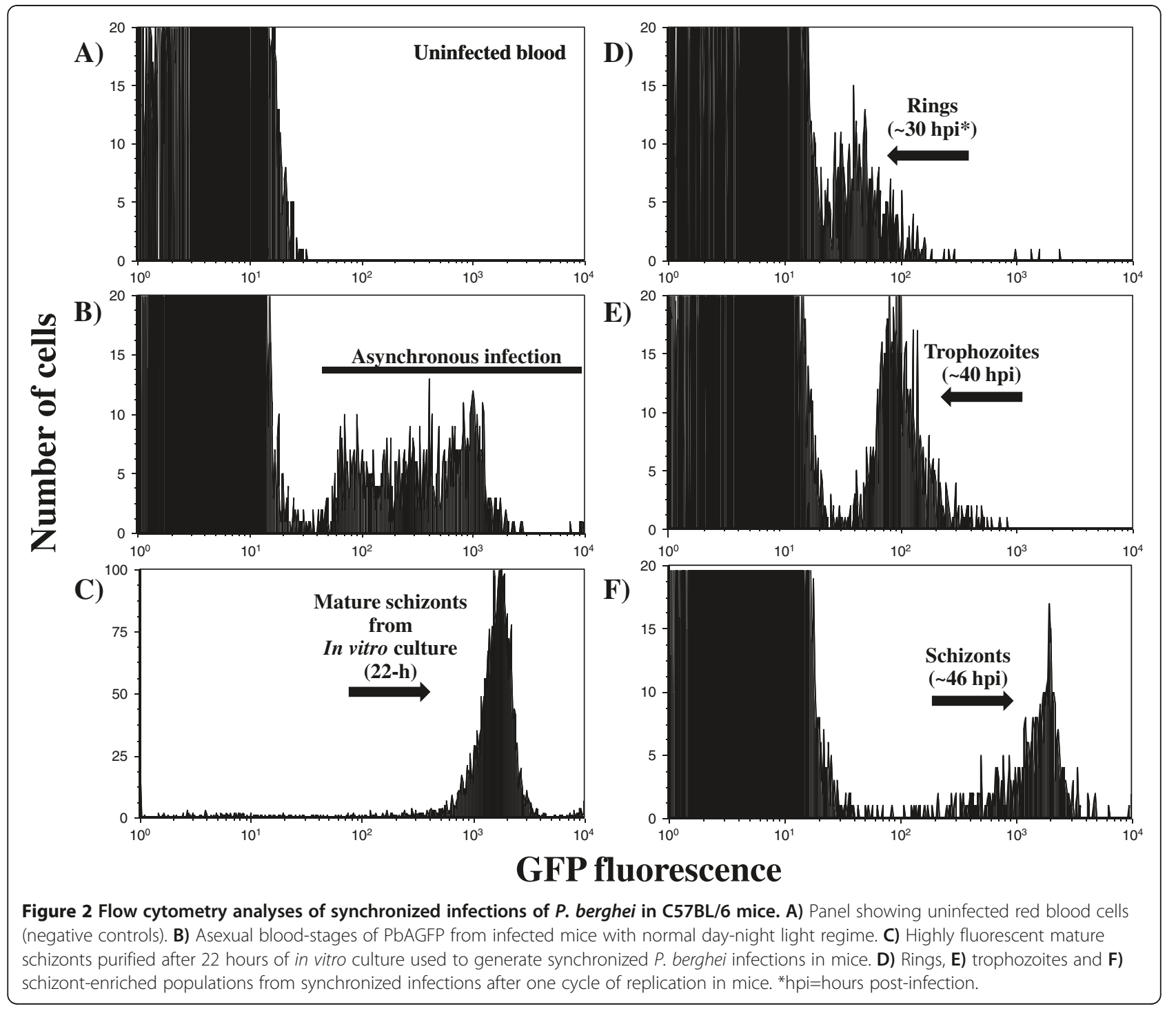

( \pm 0.02). After 4 hours of incubation, intracellular growth occurred, trophozoites predominated in the culture and the OD nearly doubled to 0.45 ( \pm 0.02 ). Ten hours after the second sample was taken (schizonts) the OD reached $1.0( \pm 0.06)$, with a slight increase at 18 hours. The OD remained stable until the end of the culture ( 22 hours) when fully mature schizonts with more than 8 nuclei were observed.

These simple growth tests confirmed that the short-culture conditions to be used in this in vitro assay supported well the parasite growth and the feasibility of this ELISA-based technique to detect it. These results also show that the maximal pLDH activity was generated when the parasites developed from early trophozoites into schizonts, which is consistent with previous reports in P. falciparum where the peak of L-lactate (product of pLDH activity) coincided with the beginning of the schizogony
$[17,20]$. There was no significantly increase in pLDH values after 16 hours of incubation when nuclear division and merozoite formation start to occur. These findings indicate that this assay is appropriate to evaluate drugs that affect the parasite's growth and maturation but not for drugs targeting DNA synthesis during schizogony. In addition, in the absence of an efficient long-term continuous culture of $P$. berghei [21,22] the drug in vitro assay proposed here is based on a single cycle. Therefore, this test is not suitable for the evaluation of drugs that have no apparent effect until division and reinvasion of new red blood cells by the daughter merozoites occur (delayed-death phenomenon described with antibacterial drugs in $P$. falciparum) and whose effect can only be estimated in the next developmental cycles [23]. For this kind of drugs, other in vitro assays for $P$. berghei based on DNA synthesis [5] and luciferase 


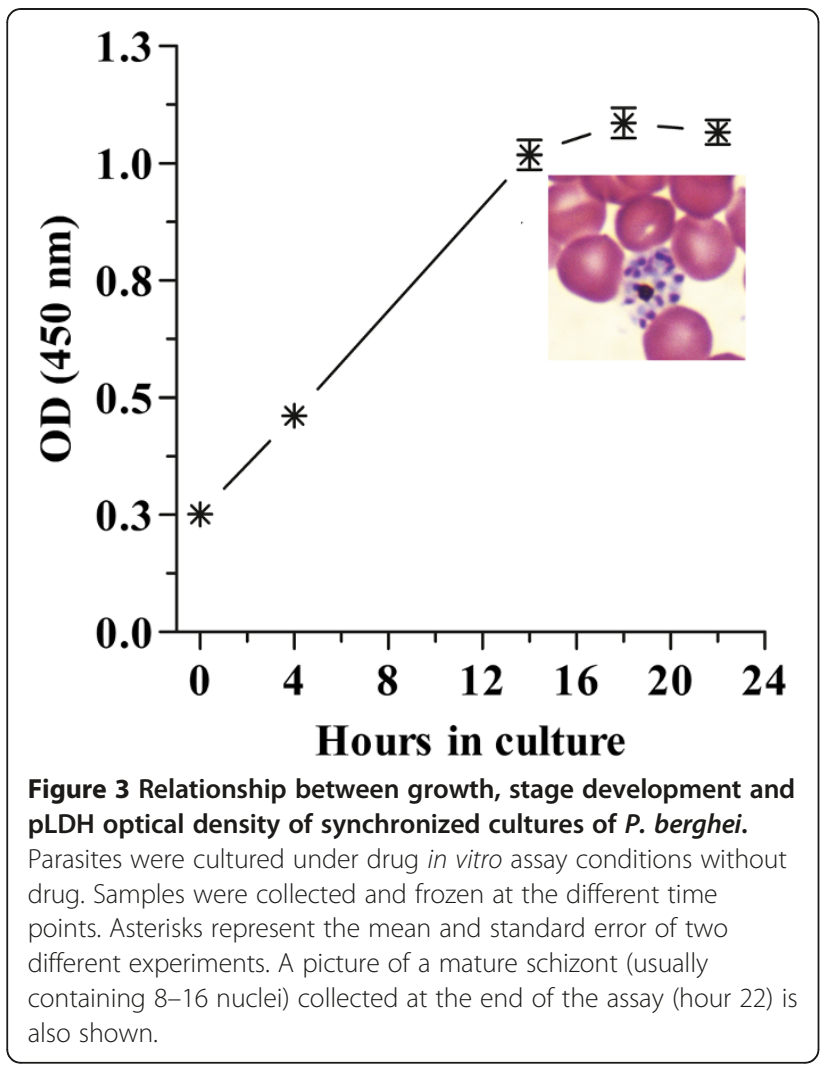

schizont-specific expression are available [6]. The recent report of a new in vitro culture technique for $P$. berghei that allows reinvasion of normal mouse red blood cells and continuous culture for over two weeks [24] might also overcome this limitation.

For the in vitro assays, early parasite stages (rings) obtained from synchronized infections were used. Parasites were incubated with the different concentrations of the anti-malarial drugs at $36.5^{\circ} \mathrm{C}$ for 22 hours. Slides confirming the fully maturation of healthy schizonts in the positive control wells were always performed at the end of each assay. Figure 4 shows the absorbance recorded for positive and negative controls during the drug in vitro assays. Absorbance values of negative controls were $0.14( \pm 0.03)$ and $0.10( \pm 0.01)$ for uninfected red blood cells and complete RPMI media, respectively. The negative controls showed significantly lower absorbance (Fisher Exact Test, $\mathrm{p}=0.0001$ ) than infected samples, regardless of the time of collection. Infected samples at time zero of growth also showed low absorbance values $(0.3 \pm 0.10)$, as expected for early stages, but significantly doubled (Fisher Exact Test, $\mathrm{p}=0.0001$ ) the OD values of the negative controls. After 22 hours of incubation, the samples from time zero of growth tripled their absorbance values to $1.1( \pm 0.2 \mathrm{SD})$. These results clearly show the suitability of the antibodies to for $P$. berghei detection.

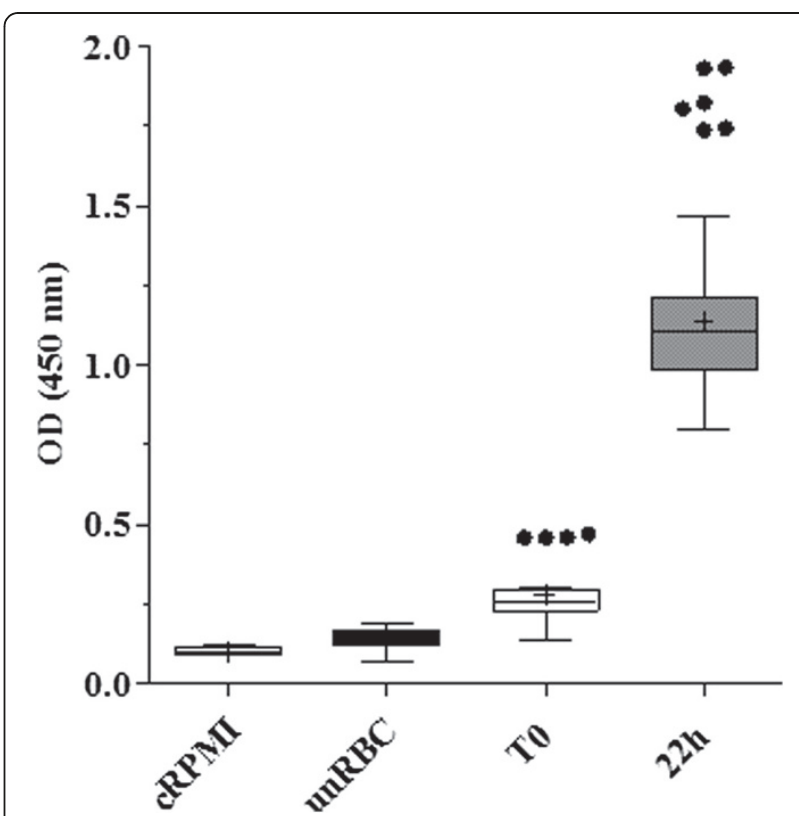

Figure 4 Optical density readings from drug in vitro assay controls. pLDH OD values for negative controls: complete RMPI media (cRPMl, $N=9$ wells), uninfected red blood cells (unRBCs, $N=$ 45 wells) and positive controls ( $N=84$ wells): infected red blood cells without drug collected at time zero of incubation (T0) and after finished the assay (22h). Wells from different assays were plotted together and at least three independent assays were performed per each group. Values are displayed in box plots, means and outliers are represented by solid crosses and black circles, respectively.

The in vitro response of $P$. berghei to common anti-malarial drugs can be observed in Figure 5 . Since no differences between the $\mathrm{IC}_{50} \mathrm{~S}$ values of the wild type $(\mathrm{PbA})$ and the transgenic line (PbAGFP) were observed, curves for both parasites were plotted together. The $\mathrm{IC}_{50}$ of chloroquine and artesunate was also investigated for PbAGFP using the micro-test [2] with similar results for both techniques (Figure 5). The $\mathrm{IC}_{50}$ values for artesunate obtained in this work $(15 \mathrm{nM})$ are in accordance with previous reports for this species [5,6]. Janse et al. [5] developed and in vitro assay for $P$. berghei analyzing the amount of parasite DNA through Hoechst staining and flow cytometry and reported $\mathrm{IC}_{50}$ values for artesunate of $11 \mathrm{nM}$. More recently, the same group developed another anti-malarial drug screening in vitro assay using a transgenic line of $P$. berghei expressing luciferase [6]. Through this highly sensitive technique, the recorded $\mathrm{IC}_{50}$ values of artesunate ranged from 4 to 26 nM. $\mathrm{IC}_{50}$ values for chloroquine in sensitive $P$. berghei strains have also been described through the use of the different techniques. Early reports of $\mathrm{IC}_{50} \mathrm{~S}$ for chloroquine sensitive lines (NK65 strain) using the radioisotopic assay ranged between $155 \mathrm{nM}$ [25] and $230 \mathrm{nM}$ [3]. A report in another murine Plasmodium 


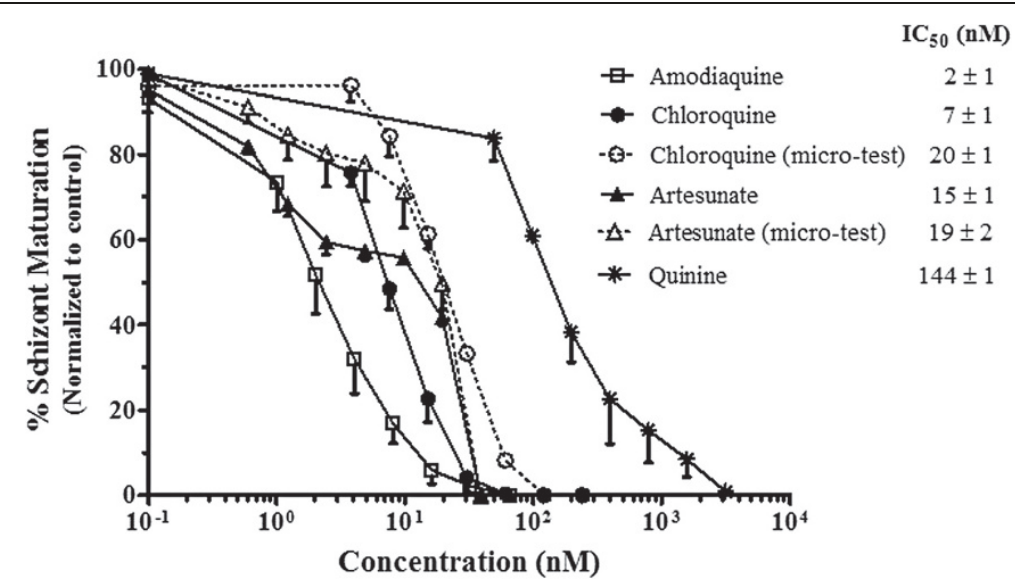

Figure 5 In vitro susceptibility of $P$. berghei to different anti-malarial drugs. Inhibition of schizont maturation by amodiaquine (squares), chloroquine (solid circles), artesunate (solid triangles) and quinine (asterisks). Curves derived from micro-test assays are displayed as dashed lines and open symbols. Each point represents the mean and the standard error of at least three independent assays for PbA and PbAGFP. The IC $C_{50}$ values and standard error of the media are shown in the legend.

species Plasmodium chabaudi described an $\mathrm{IC}_{50}$ value of chloroquine of $30 \mathrm{nM}$ using the radioisotopic technique [26]. More recently, $\mathrm{IC}_{50}$ values of $30 \mathrm{nM}$ were also described in $P$. berghei using the luciferase assay [6]. In the present study, the $\mathrm{IC}_{50} \mathrm{~S}$ values for chloroquine sensitive lines (PbA and PbAGFP) were $7 \mathrm{nM}$ and $20 \mathrm{nM}$ using the pLDH ELISA and the micro-test, respectively (Figure 5); both values are within the range of $\mathrm{IC}_{50}$ values described for sensitive chloroquine strains of Plasmodium in rodents $[3,6,25,26]$ and similar to those reported in P. falciparum [10,27-30] and Plasmodium vivax [24,31]. The reports of $\mathrm{IC}_{50} \mathrm{~s}$ for amodiaquine and quinine in $P$. berghei are more restricted, mainly derived from the radioisotopic assays: $430 \mathrm{nM}$ and $1500 \mathrm{nM}$, respectively [3]; another study showed an $\mathrm{IC}_{50}$ of $210 \mathrm{nM}$ for quinine-HCL using again the radioisotopic technique [25]. In this work was found that $P$. berghei ANKA lines were sensitive to amodiaquine $\left(\mathrm{IC}_{50}\right.$ of $\left.2 \mathrm{nM}\right)$ and quinine ( $\mathrm{IC}_{50}$ of $\left.144 \mathrm{nM}\right)$. These values have been also described in sensitive strains of $P$. falciparum [10,27-30] and $P$. vivax [32]. However, comparison of in vitro $\mathrm{IC}_{50}$ data among different Plasmodium species should be cautiously made and was not the purpose of the present study. Comparisons of these results, with previous reports in $P$. berghei can be also limited since available $\mathrm{IC}_{50} \mathrm{~S}$ have been obtained through different techniques and conducted with different strains, hosts, drug dilution protocols and under diverse parameters of parasitaemia and haematocrit that can influence the $\mathrm{IC}_{50}$ results [27]; moreover early in vitro assays described in P. berghei were usually conducted without synchronization procedures $[3,25,26]$.
This ELISA method provides a simple procedure to determine $\mathrm{IC}_{50} \mathrm{~s}$ for anti-malarial drugs in vitro using $P$. berghei. Since studies focusing on the identification of novel drugs often involve the testing of the in vivo efficacy of drug candidates in small animal (rodent) models of malaria, the availability of simple assays to determine the in vitro drug-sensitivity of rodent parasites is useful. Specifically, this assay may help to determine whether a discrepancy between in vitro $P$. falciparum drugsensitivity and in vivo rodent parasite drug-sensitivity is the result of intrinsic differences between the two parasite species or may be due to pharmacokinetic or pharmacodynamic characteristics of the drug in a live animal.

\section{Conclusion}

In this study, the development of an ELISA-based in vitro drug assay for P. berghei is reported. This technique is easy to implement, fast (less than 3 hours), safe (avoids the use of radioisotopes) and economical (not requiring expensive equipment such as beta counters, flow cytometers or luminometers). Although the development of synchronized infections in mice is time consuming, this is a straightforward procedure which can be easily implemented in laboratories working with murine models. This in vitro assay represents a robust and useful alternative for the screening of new anti-malarial compounds in the mouse model of P. berghei.

\section{Abbreviations}

WHO: World Health Organization; LDH: Lactate dehydrogenase; pLDH: Parasite Lactate dehydrogenase; ELISA: Enzyme-linked immunosorbent assay; IP: Intraperitoneally; PbA: Plasmodium berghei ANKA, PbAGFP, Plasmodium berghei ANKA GFP; MR4: Malaria Research and Reference Reagent Resource Center; NIH: National Institutes of Health; PBS: Phosphate 
buffered saline; RPMI: Roswell Park Memorial Institute; IV: Intravenously; OD: Optical density; IC $C_{50}$ : Half maximal inhibitory concentration; SD: Standard deviation; HABA: 4'-hydroxyazobenzene-2-carboxylic acid; DELI: Double-site enzyme-linked lactate dehydrogenase immunodetection assay; BSA: Bovine serum albumin; TMB: 3,3',5,5'-tetramethybenzidine; unRBC: Uninfected red blood cell; cRMPI: Complete RMPI media.

\section{Competing interests}

Authors do not have any competing interests.

\section{Authors' contributions}

The work was carried out in collaboration between all authors. POS and LJMC designed experiments. POS carried out the laboratory experiments, analysed the data, interpreted the results and wrote the manuscript. ED assisted in FACS experiments and FCS Express software analyses. LMC conceived the study, interpreted results and revised the manuscript. JAF and JN discussed the results and revised the manuscript. All authors have approved the final manuscript.

\section{Acknowledgments}

This work was supported with funds from the United States National Institutes of Health (NIH) grants R01-HL087290 and R01-Al082610 (L.J.M.C.). J.N. and E.D. were supported by NIH grant RO1-EB003824. We are indebted to Dr. Michael Makler (Flow Inc., Portland, OR) for kindly providing the monoclonal antibody $14 \mathrm{C} 1$ and for productive discussions. We also thank Diana Adams and Haleigh Howard for mice care. The authors dedicate this paper in tribute to Michael T. Makler $\left({ }^{*} 11 / 17 / 1936\right.$ †05/13/2012), a great man of his time, for his enormous contributions to the fight against malaria.

\section{Author details}

'La Jolla Bioengineering Institute, 3535 General Atomics Court, Suite 210, San Diego, California (CA) 92121, USA. ${ }^{2}$ Laboratory of Malaria Research, Oswaldo Cruz Institute, Fiocruz, 21040-900, Rio de Janeiro, Brazil.

Received: 27 September 2012 Accepted: 31 October 2012 Published: 5 November 2012

\section{References}

1. Peters W, Robinson BL: The chemotherapy of rodent malaria. XLVII. Studies on pyronaridine and other Mannich base antimalarials. Ann Trop Med Parasitol 1992, 86:455-465

2. Rieckmann KH, Campbell GH, Sax LJ, Mrema JE: Drug sensitivity of Plasmodium falciparum. An in-vitro microtechnique. Lancet 1978, 1:22-23.

3. Platel DF, Mangou F, Tribouley-Duret J: High-level chloroquine resistance of Plasmodium berghei is associated with multiple drug resistance and loss of reversal by calcium antagonists. Int J Parasitol 1998, 28:641-651.

4. Janse $\mathrm{CJ}$, Van Vianen PH: Flow cytometry in malaria detection. Methods Cell Biol 1994, 42:295-318.

5. Janse CJ, Waters AP, Kos J, Lugt CB: Comparison of in vivo and in vitro antimalarial activity of artemisinin, dihydroartemisinin and sodium artesunate in the Plasmodium berghei-rodent model. Int J Parasitol 1994, 24:589-594

6. Franke-Fayard B, Djokovic D, Dooren MW, Ramesar J, Waters AP, Falade MO, Kranendonk M, Martinelli A, Cravo P, Janse C: Simple and sensitive antimalarial drug screening in vitro and in vivo using transgenic luciferase expressing Plasmodium berghei parasites. Int J Parasitol 2008, 38:1651-1662.

7. Vander Jagt DL, Hunsaker LA, Heidrich JE: Partial purification and characterization of lactate dehydrogenase from Plasmodium falciparum. Mol Biochem Parasitol 1981, 4:255-264.

8. Vander Jagt DL, Hunsaker LA, Campos NM, Baack BR: D-lactate production in erythrocytes infected with Plasmodium falciparum. Mol Biochem Parasitol 1990, 42:277-284.

9. Makler MT, Ries JM, Williams JA, Bancroft JE, Piper RC, Gibbins BL, Hinrichs DJ: Parasite lactate dehydrogenase as an assay for Plasmodium falciparum drug sensitivity. AmJTrop Med Hyg 1993, 48:739-741.

10. Druilhe $P$, Moreno A, Blanc $C$, Brasseur PH, Jacquier P: A colorimetric in vitro drug sensitivity assay for Plasmodium falciparum based on a highly sensitive double-site lactate dehydrogenase antigen-capture enzymelinked immunosorbent assay. AmJTrop Med Hyg 2001, 64:233-241.
11. Desjardins RE, Canfield CJ, Haynes JD, Chulay JD: Quantitative assessment of antimalarial activity in vitro by a semiautomated microdilution technique. Antimicrob Agents Chemother 1979, 16:710-718

12. Franke-Fayard B, Trueman H, Ramesar J, Mendoza J, van der Keur M, van der Linden R, Sinden RE, Waters AP, Janse CJ: A Plasmodium berghei reference line that constitutively expresses GFP at a high level throughout the complete life cycle. Mol Biochem Parasitol 2004, 137:23-33.

13. Janse CJ, Waters AP: Plasmodium berghei: the application of cultivation and purification techniques to molecular studies of malaria parasites. Parasitol Today 1995, 11:138-143.

14. Janse CJ, Ramesar J, Waters AP: High-efficiency transfection and drug selection of genetically transformed blood stages of the rodent malaria parasite Plasmodium berghei. Nat Protoc 2006, 1:346-356.

15. Noedl H: Non linear evaluation of malaria drug sensitivity data (HN-NonLin V1.1). Bangkok, Thailand: Armed Forces Research Institute for Medical Sciences; 2002. http://www.meduniwien.ac.at/user/harald.noedl/malaria/download.html.

16. Piper RC, Buchanan I, Choi YH, Makler MT: Opportunities for improving pLDH-based malaria diagnostic tests. Malar J 2011, 10:213.

17. Basco LK, Marquet F, Makler MM, Le Bras J: Plasmodium falciparum and Plasmodium vivax: lactate dehydrogenase activity and its application for in vitro drug susceptibility assay. Exp Parasitol 1995, 80:260-271.

18. Lambros C, Vanderberg JP: Synchronization of Plasmodium falciparum erythrocytic stages in culture. J Parasitol 1979, 65:418-420.

19. Deharo E, Gautret P, Ginsburg H, Chabaud AG, Landau I: Synchronization of Plasmodium yoelii nigeriensis and P. y. killicki infection in the mouse by means of Percoll-glucose gradient stage fractionation: determination of the duration of the schizogonic cycle. Parasitol Res 1994, 80:159-164.

20. Pfaller MA, Krogstad DJ, Parquette AR, Nguyen-Dinh P: Plasmodium falciparum: stage-specific lactate production in synchronized cultures. Exp Parasitol 1982, 54:391-396.

21. Smalley ME, Butcher GA: The in vitro culture of the blood stages of Plasmodium berghei. Int J Parasitol 1975, 5:131-132.

22. Ramaiya ML, Kamath VR, Renapurkar DM: Long-term in vitro cultivation of Plasmodium berghei. Int J Parasitol 1987, 17:1329-1331.

23. Goodman CD, Su V, McFadden GI: The effects of anti-bacterials on the malaria parasite Plasmodium falciparum. Mol Biochem Parasitol 2007, 152:181-191.

24. Jambou R, El-Assaad F, Combes V, Grau GE: In vitro culture of Plasmodium berghei-ANKA maintains infectivity of mouse erythrocytes inducing cerebral malaria. Malar J 2011, 10:346.

25. Kamiyama T, Matsubara J: Application of a simple culture of Plasmodium berghei for assessment of antiparasitic activity. Int J Parasitol 1992, 22:1137-1142.

26. Sohal AK, Arnot DE: Plasmodium chabaudi: a short-term in vitro culture method and its application to chloroquine resistance testing. Exp Parasitol 1993, 76:314-317.

27. Basco LK: Field application of in vitro assays sensitivity of human malaria parasites antimalarial drugs. Geneva: World Health Organization Press; 2007:23-29. 89-104.

28. Basco LK, Ringwald P: Molecular epidemiology of malaria in Cameroon. XXIV. Trends of in vitro antimalarial drug responses in Yaounde, Cameroon. AmJTrop Med Hyg 2007, 76:20-26.

29. Pradines B, Tall A, Parzy D, Spiegel A, Fusai T, Hienne R, Trape JF, Doury JC: In-vitro activity of pyronaridine and amodiaquine against African isolates (Senegal) of Plasmodium falciparum in comparison with standard antimalarial agents. J Antimicrob Chemother 1998, 42:333-339.

30. Pradines B, Fusai T, Daries W, Laloge V, Rogier C, Millet P, Panconi E, Kombila M, Parzy D: Ferrocene-chloroquine analogues as antimalarial agents: in vitro activity of ferrochloroquine against 103 Gabonese isolates of Plasmodium falciparum. J Antimicrob Chemother 2001, 48:179-184.

31. Russell BM, Udomsangpetch R, Rieckmann KH, Kotecka BM, Coleman RE, Sattabongkot J: Simple in vitro assay for determining the sensitivity of Plasmodium vivax isolates from fresh human blood to antimalarials in areas where P. vivax is endemic. Antimicrob Agents Chemother 2003, 47:170-173.

32. Hasugian AR, Tjitra E, Ratcliff A, Siswantoro $H$, Kenangalem E, Wuwung RM, Purba $\mathrm{HL}$, Piera KA, Chalfien F, Marfurt J, et al: In vivo and in vitro efficacy of amodiaquine monotherapy for treatment of infection by chloroquineresistant Plasmodium vivax. Antimicrob Agents Chemother 2009, 53:1094-1099.

doi:10.1186/1475-2875-11-366

Cite this article as: Orjuela-Sánchez et al:: A lactate dehydrogenase ELISA-based assay for the in vitro determination of Plasmodium berghei sensitivity to anti-malarial drugs. Malaria Journal 2012 11:366. 